\title{
Grammatical rules are discrete, not weighted, and not vulnerable
}

\author{
Hubert Haider \\ University of Salzburg
}

\begin{abstract}
The paper defends the following positions: Grammaticality and acceptability must not be regarded as virtually coextensive. Grammaticality is discrete; acceptability is gradient. Acceptability can be measured directly; grammaticality can only be tested indirectly. Acceptability is a reflex of performance factors interacting with the mentally represented grammatical rule system; grammaticality is a theoretical concept. Acceptability is a theory-independent behavioral property; grammaticality is defined by the cognitively encapsulated grammar, which is the empirical research target of grammar theory.
\end{abstract}

\section{Introduction}

The principal point of the paper is this: Grammaticality is discrete; acceptability is gradient. Grammaticality stands for accordance with grammatical rules and principles of a given language. Arguably, these rules are discrete functions. Acceptability, on the other hand, is a compound result of everything that influences the linguistic behaviour of (native) language users, especially when confronted with judgement tasks. Their results are - as for any complex behavioural task - variable and gradient. Grammaticality, on the other hand, characterizes any expression as either well-formed or ill formed with respect to the rules that apply. Therefore, grammaticality is a yes-or-no quality rather than a matter of more-or-less. If a given expression matches up, it is well formed; if it does not, it is in violation of rules and therefore ill-formed. This is also true for models such as Optimality Theory that employ a technical concept of vulnerable

Ken Ramshøj Christensen, Henrik Jørgensen \& Johanna L. Wood (eds.). 2019.

The Sign of the V-Papers in Honour of Sten Vikner.

Dept. of English, School of Communication \& Culture, Aarhus University, pp. 205-226, doi:10.7146/aul.348.96. (C) The author(s). 
rules (see Keller 2006). In OT, a grammatical expression may violate lower ranked rules. Nevertheless, each rule applies discretely. It is obeyed or violated discretely. Even in a probabilistic version of OT (Boersma $\&$ Hayes 2001), the rules apply discretely. Probabilities are attached to alternative rule rankings.

If a rule of grammar appears to be fuzzy, its fuzziness is not a property of grammar but of the conditions under which the expressions in question are put to use or tested. For a syntactician, the assumption of weighted rules of grammar would be a capitulation in face of the complexities of grammar systems. Weighted rules have their place in language engineering, for instance in AI applications. ${ }^{1}$ Linguistic expressions are not " $x y \%$ grammatical", and the localization of an item in its appropriate syntactic structure is not ruled by any uncertainty principle. It is conceptual fuzziness when people don't clearly distinguish between the concepts of (discrete) grammaticality and (gradient) acceptability.

\section{Acceptability is not grammaticality and vice versa}

Grammaticality cannot be measured directly. What "grammaticality judgement tasks" measure is acceptability. Grammaticality is a grammardependent property of a potentially infinite set of expressions. An expression is grammatical if it meets the requirements of the applicable grammar. If it does not, it is not grammatical. What is the 'applicable' grammar? It is the mental knowledge system that enables a native speaker to process a language. The knowledge system is a cognitive 'app' in the ensemble of cognitive modules that cooperate in language processing. Moreover, speakers cannot be expected to be completely uniform in their acceptability judgements because of minimal cross-individual differences in their mental grammars. There is no completely homogenous language community. This notwithstanding, a surprising property of human grammars is their high degree of cross-individual uniformity.

The empirical object of linguistic investigations is the grammar as a cognitively represented knowledge system. It is modelled within a theory of grammar. In language science, the model of the grammar of a particular language is - just as in any empirical discipline - always work-in-progress. The status of such a model is that of a complex scientific hypothesis.

1 See e.g. Mohri \& Nederhof (2001: 257): "Grammars used in many applications such as those related to speech processing incorporate weights. These weights, which are often interpreted as probabilities, are used to rank different hypotheses for the purpose of disambiguation." 
Linguists investigate and test their models of grammar by confronting them with data gained from as many and diverse sources as available: informant judgements, cross-linguistic data, data from psycho- and neurolinguistics, and so on. When linguists claim to have empirically measured grammaticality, they have measured acceptability, which is then interpreted as a reflex of grammaticality. Therefore, linguists often fail to appreciate the highly indirect relation between acceptability and grammaticality; see Cowart (1997, ch.1) for details. It is virtually impossible to receive full consent from informants even for a stimulus set that contains nothing but grammatical expressions. Conversely, a high percentage of flatly ungrammatical expressions may be rated "acceptable" if the test items are smartly chosen (see section 5 on acceptable ungrammaticality). But even carefully designed test batteries cannot be immunized against a percentage of false-positive and false-negative outcomes. Statisticians refer to these inevitable test imperfections as type I and type II errors. These errors are caused by various kinds of imperfection, as for instance an - in hindsight suboptimal test design with unforeseen irrelevant but distracting stimulus qualities, uncooperative informants, distracted informants, informants who partially misunderstand their task, and so on. This is true for small-scale studies as well as for large-scale ones.

\section{Vulnerabilities}

"Vulnerability" is a multifaceted concept. It can be - and in fact is construed in several distinct ways. First, vulnerability can be seen as characteristic of regulative rules (see Searle 1969:51). Such a rule is something between "should" and "must". For instance, you must not drive faster than the traffic limit, although you can, with the risk of being fined if noted by police. Rules of grammar, on the other hand, are constitutive rules. The rules constitute the grammar and the grammar defines grammaticality. If expressions that someone utters are systematically ill formed in standard German, this person does not violate rules of standard German but merely speaks another variety of German, as for instance "Kiezdeutsch". ${ }^{2}$

Second 'vulnerable rules' may be interpreted as non-discrete, weighted grammatical rules. If one misapplies a case assignment rule in German, the resulting utterance may be felt to be more deviant than ignoring a locality constraint when fronting a phrase to the clause initial position.

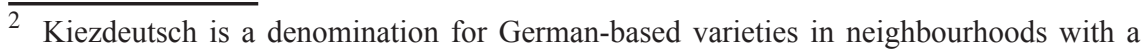
high proportion of youngsters whose L1 is not German. This is not 'bad German' but rather a social variety of its own. 
These 'feelings' are acceptability attitudes. The intensity of these feelings depends on the amount and quality of repair efforts when mapping the stimulus onto its well-formed variant. Finally, 'vulnerable' may be used as a characterization of the stability of a rule or a rule system across time and space. This squib will focus on the first two of these three notions.

\section{Discrete, not continuous}

Let us start with the disputed (non-)discrete status of grammatical rules and principles. In set theoretical terms, grammatical rules may be conceived of as "indicator functions" aka "characteristic functions" for defining the set of grammatically well-formed expressions $E$, given a grammar G. Such a function indicates the membership of an element of $E$ by assigning the value 1 to it. All elements not in the set $E$ are assigned the value 0 . Such a function is a discrete function. Correspondingly, a set of data is discrete if the values belonging to the set are distinct and separate, that is, non-continuous. This is true for any indicator function. If grammatical rules are discrete functions, they characterize two sets, namely the set of grammatically well-formed expressions and its complementary set. From this point of view, a grammar as the ensemble of grammatical rules and principles of a language $\mathrm{L}$ is a complex indicator function for wellformedness in L. It discretely characterizes the set of grammatically wellformed expressions.

If, on the other hand, a set of data is said to be continuous or gradient, the values belonging to the set can in principle take on any value within a specified interval. In the graph of a continuous function, the value points are connected with a continuous line since every point in this model is in a meaningful relation to the modelled reality. Continuous data require a measuring device for measuring the exact value on a continuous scale. ${ }^{3}$ If grammatical rules are non-discrete, that is, continuous, every expression gets assigned some value on a scale, let us say the set of rational numbers between 0 (= fully deviant) and 1 (= fully acceptable). To say that the data quality is continuous does of course not presume that the data qualities spread over the whole interval of a scale. Typically, they are scattered around attractor regions, that is, potentially overlapping regions that are characteristic of acceptable vs. unacceptable stimuli.

Let us recapitulate. If grammatical rules are discrete functions, the set of values for the grammaticality of linguistic expressions consists of

3 The exact position on a temperature scale can be measured with a thermometer. Featherston (2008) has proposed a linguistic "thermometer method" for acceptability testing. 
only two values, namely 0 and 1 . If grammatical rules were continuous functions, they could in principle map expressions on an infinite set of numerical values, ranging for instance between zero and one.

Let us assume an expression is mapped on the value 0,683 . What could this mean? Surely, it does not mean that the expression is $68,3 \%$ grammatical and $31,7 \%$ ungrammatical. A source of such a value could be this. When 1.000 persons are confronted with a given expression and 683 of them rate the expression as acceptable, it is characterized by the value 0,683 . Another interpretation might be as follows: A single person is confronted with 1000 instances of a type of construction, for instance the middle of the German causative construction in combination with and without a semantically empty $e s^{4}$ (it) as subject. This person opts for es in 683 cases, and in 317 instances for not using es. Such a result might be a basis for assigning the value 0.683 to the construction with es and the value 0.317 to the construction without es. Another possibility is this: The decimal number could be the mean of the z-scores of a magnitudeestimation task. The group result characterizes the given expression as half way between acceptable and deviant.

Such numbers are measuring results. Without a meaningful model, numbers are nothing but data points. They only represent the outcome of a measurement. In the worst case, these are values of a random distribution. One thing should be clear, however: It is pointless to assume for an item that its grammaticality value is 0,683 .

Another intricate property of acceptability judgements is the fact that they are graded even across fully grammatical stimuli. ${ }^{5}$ The examples $(1 \mathrm{a}, \mathrm{b})$ and $(2 \mathrm{a}, \mathrm{b})$ are corpus data. In (1a), the accusative is licit, but only in the presence of a semantically empty subject, viz. es (it). Therefore (1c) is deviant. On the other hand, the nominative (1b) is incompatible with the presence of a subject es. That's why (1d) is deviant (see Haider 2019). (1) a. Hier lässt es sich den Acc $_{\text {Sommer gut verbringen. }}$
here lets it REFL the summer well spend 'The summer can be spent well here.'

4 Example: Damit lässt (es) sich gut leben [it-with lets (it) itself well live - 'One may live well with it']

5 For instance, Schachter and Yip (1990) found that both English natives as well as L2 learners rate long-distance subject wh-fronting lower than object fronting, although both constructions are grammatical. 
b. Hier lässt sich der $_{\text {Nom }}$ Sommer gut verbringen.
here lets REFL the summer well spend 'The summer can be spent well here.' well spend 'The summer can be spent well here.'

c. *Hier lässt sich den ${ }_{\text {Acc }}$ Sommer gut verbringen. here lets REFL the summer well spend

d. *Hier lässt es sich $\operatorname{der}_{\text {Nom }}$ Sommer gut verbringen. here lets it REFL the summer well spend

First of all, $(1 \mathrm{a}, \mathrm{b})$ are expected to receive significantly higher acceptability rates than (1c,d). Second, (1c) is likely to be rated less deviant than (1d). On the one hand, there are easily available repair options for the missing es in spoken language, ${ }^{6}$ and on the other hand, es is optional in the intransitive construction (see fn. 4). Third, the construction (1a) is infrequent ${ }^{7}$ and employed with a smaller class of verbs as illustrated in $(2 \mathrm{a}, \mathrm{b})$ vs. $(2 \mathrm{c}, \mathrm{d})$, hence this construction is likely to receive lower acceptability ratings than (1b).

(2) a. Bei Kastanien und Glühwein lässtes sich den Acc with chestnuts and mulled-wine lets it REFL the

Alltagsstress vergessen. ${ }^{8}$ daily-grind-stress forget

'With chestnuts and mulled wine, the daily-grind-stress is easy to forget.'

b. So lässt es sich $\operatorname{den}_{\text {Acc }}$ 19. Geburtstag feiern. ${ }^{9}$ so lets it REFL the 19th birthday celebrate 'In this way, the $19^{\text {th }}$ birthday is fine to celebrate.'

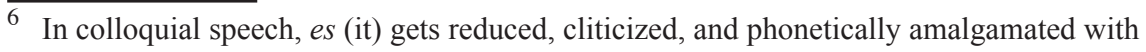
the sibilant of the following reflexive.

7 A Google search (Aug. 1 ${ }^{\text {st }}, 2019$ ), restricted to news sites, produced 4680 hits for „Hier lässt sich der", but only 270 hits for "Hier lässt es sich den".

8 https://www.schmalzerhof.it/winter.html

9 https:/www.ok-magazin.de/people/news/sexy-bikini-birthday-bash-so-feierte-kyliejenner-ihren-19-42415.html 
c. ?Mit diesem Köder lässt es sich auch einen Acc with this bait lets it REFL also a

großen Fisch fangen.

big fish catch

d. ?Über dieses Thema lässt es sich nur einen ${ }_{\text {Acc }}$ about this topic lets it REFL only a

kurzen Vortrag halten. short lecture give

How to deal with such results? Is (1a) in a measurable relation to (1b)? Is (1b) 'more' grammatical than (1a) or (2a,b)? Obviously, such interpretations would be pointless. Both, (1a) and (1b), are grammatical, even if one may be preferred over the other. If informants prefer $(1 b)$, this may be the effect of promoting a more familiar construction. The degrading effect is stronger for $(2 \mathrm{c}, \mathrm{d})$, for reasons that have not been investigated yet.

Let us proceed to more general types of confounds, namely "acceptable ungrammaticality" 10 ; see Frazier (2015); Haider (2011), Phillips et. al 2011) and overstrained test subjects. (3a,b) are German examples of acceptable ungrammaticality, that is, of expressions that tend to be rated as acceptable although they are ungrammatical. In fact, these are last-resort kind of responses in a grammatical rule conflict, as will be explained.

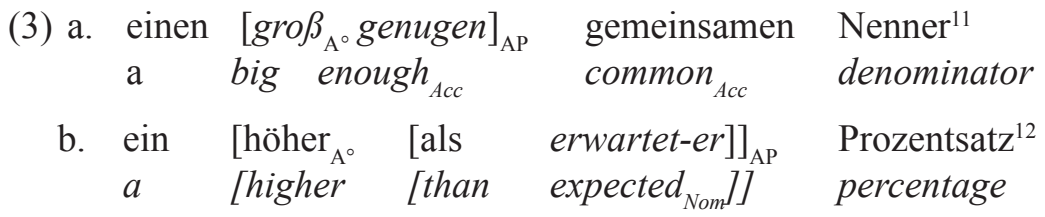

Speakers who use or accept $(3 \mathrm{a}, \mathrm{b})$ apparently accept it because it is the less deviant option in comparison to the variant (4), with a correctly inflected head but violating a strict grammatical requirement, namely adjacency between the head of the pre-NP attribute and the NP.

\footnotetext{
10 "Acceptable ungrammaticality is a theoretical notion whereby the best theory of grammar and best theory of processing conspire to account for how an utterance not generated by the grammar nevertheless tends to be accepted by native speakers at least under some conditions." (Frazier 2015: 8).

11 https://www.welt.de/debatte/kommentare/article171405553/Die-CSU-ist-anders-alsalle-anderen-Parteien.html

12 https://www.aerztezeitung.de/praxis_wirtschaft/unternehmen/article/639430/roche-stoppt-entwicklung-taspoglutid.html
} 
$\begin{array}{cccc}\text { (4) a. *einen } & {\left[\text { großen }_{\mathrm{A}^{\circ}} \text { genug }\right]_{\mathrm{AP}}} & \text { gemeinsamen } & \text { Nenner } \\ a & {\left[\text { big }_{\text {Acc }} \text { enough }\right] \quad \text { common }_{\text {Acc }}} & \text { denominator } \\ \text { b. *ein } & {[\text { höherer } \quad[\text { als erwartet }]]_{\mathrm{AP}}} & \text { Prozentsatz } \\ a & \text { higher } & \text { percentage }\end{array}$

When uttering $(3 a, b)$, people are flouting rules of grammar, but they don't do it wilfully. They do it because they are at a loss. They use such versions as the grammatically least harmful way of escaping a grammatical rule conflict they find themselves entangled in (Haider 2018a). It is a catch-22 dilemma. On the one hand, the head of an attributive AP must be adjacent to the NP. On the one hand, genug (enough) or a comparative phrase must follow the head, thereby destroying adjacency.

These two requirements cannot be met simultaneously. So, speakers 'cheat'. They put agreement inflection on an adjacent, inflectable item as if it were the head of the AP, which it is not. $(3 a, b)$ contain an inflected, $\mathrm{NP}$-adjacent item and therefore they are judged as less deviant than the ungrammatical $(4 a, b)$.

These examples are instances of flouting a rule under special circumstances. Speakers who utter $(3 a, b)$ do not employ a vulnerable rule of grammar; they interfere with a rule of grammar. They use an expression despite its ungrammaticality. However, this does not constitute a case of a "vulnerable rule", just like re-catching a dropped ball before it hits the ground is not a violation of the law of gravitation. If the ball remains above the ground, it does so only because of the energy one exerts. And the expressions in (3) exist only because people invest energy in transgressing a rule of grammar. ${ }^{13}$

Some speakers even try to obey the incompatible demands and resort to $(5 \mathrm{~b})$. They inflect the adjectival head and the adjacent item. Thereby, they try to meet both demands, that is, the adjectival head receives its agreement inflection as the head of the AP, and in addition, an NP-adjacent head receives the same agreement morphology and is turned into the fake head of the phrase. If such an item is not inflectable, the result is robustly unacceptable $(5 \mathrm{c})$. It is psycho-linguistically intriguing that speakers resort to 'solutions' such as exemplified by (3) and (5b) at all, since at least in the case of an intervening comparative PP, removing the intervener by extraposing it, as in (5d), would be the perfect solution.

13 Such efforts are measurable, for instance, in ERP-experiments. 
(5)
*ein [höherer
a $\quad$ [higher $_{\text {Agr }}$
[als erwartet $]]_{\mathrm{AP}}$
[than expected]]
Prozentsatz
b. \#ein [höherer ${ }_{\mathrm{Agr}}$
[als erwarteter $\left.\left.{ }_{\mathrm{Agr}}\right]\right]_{\mathrm{AP}}$
c. *ein [höherer
[als letztes Jahr] $]_{\mathrm{AP}}$
a [higher
[than last year]]
percentage
$\begin{array}{cl}\text { d. } & \text { ein } \\ a & \text { [höherer ] } \\ & \text { [higher }{ }_{\text {Agr }} \text { ] }\end{array}$
Prozentsatz
percentage
Prozentsatz ${ }^{14}$
Prozentsatz
percentage $^{15}$
[als erwartet] $]_{\mathrm{AP}}$
[than expected]

If informants rate ( $3 b)$ and (5b) in the range between acceptable and mildly deviant, such a rating is not a grammaticality judgement. Informants do not judge 'grammaticality'; they gauge 'acceptability'. If they end up with a choice between two deviant options, the least deviant one will be picked and rated as (nearly) acceptable. This behaviour must not be misinterpreted as a well-formedness vote. There is no need for a grammar that assigns some value between 0 and 1 to an utterance like $(3 a, b)$. They are ungrammatical. The fact that they nevertheless tend to be regarded as at least marginally acceptable is not a fact about grammar but a fact about putting grammars to use, that is, about acceptability.

Bech (1963) described an unavoidable grammatical catch-22 dilemma, that is, a rule constellation without escape. He was the first to realize that grammars may entail rule conflicts. The title of Bech's paper, Grammatische Gesetze im Widerspruch (grammatical laws in contradiction), is a succinct declaration of the topic. His prime example is a conflict in German infinitival IPP constructions (= infinitivus pro participio, aka Ersatzinfinitiv), illustrated in (6). On the one hand, the infinitival marker $z u$ (to) must occur on the final verb of an infinitival clause. ${ }^{16}$ On the other hand, a clausefinal auxiliary like haben ('have') must be preposed across modals and other verbs. This is known as the IPP construction. (6a) is an example in which the trigger auxiliary, viz. haben (have), is finite. The fully parallel infinitival counterpart (6b) is ungrammatical because of the positioning of $z u$. In German, unlike Dutch, the infinitival marker of the infinitival clause

${ }^{14}$ For example: http://www.patent-de.com/20000224/DE19856341C1.html

15 Here is a single corpus find with a 'fake' Saxon genitive: "The wholesale price indices registered a higher-than-last-years rise".

16 This is a peculiarity of German. In Dutch, te is positionally unrestricted: "te hebben moeten doen" (to have must ${ }_{\text {Inf }}$ do). German: "hat ${ }_{\text {finite }}$ tun müssen" vs. *" $z u$ haben tun müssen" - \#"haben tun $z u$ müssen". 
has to occur clause-final. In (6c), $z u$ occurs on the final verb, as required, but it is attached to the wrong verb. It ought to be attached to the very same verb that is the finite verb in the corresponding finite clause (6a), namely haben.

(6) a. dass man das Problem nicht hat beseitigen können / beseitigen hat that one the problem not has ${ }_{\text {Agr }}$ resolve can ${ }_{I n f} \quad$ / resolve has ${ }_{A g r}$ können

$c a n_{\text {Inf }}$ 'that one was not able to resolve the problem'

b. *ohne das Problem zu haben beseitigen können without the problem to have resolve can Inf / *beseitigen $z u$ haben können can $_{\text {can }}$ have

c. \#ohne das Problem haben beseitigen zu können ${ }^{17}$ without the problem have to resolve can Inf / resolve to haben zu können

to can ${ }_{\text {can }}$

(6c) is generally rated better than (6b) and is in fact recommended by prescriptive grammarians. In several elicitation tests with freshman students of linguistics, however, more than a third of the test subjects turned out to be unable to produce a result like (6c). They capitulated (see Haider 2011). This construction apparently is not part of the competence of native German speakers, even after more than twelve years of literacy schooling. Likewise, professional writers avoid the infinitival IPP construction. The novel Buddenbrooks by Thomas Mann, for example, does not contain a single token of an infinitival IPP construction although in this novel, the finite IPP construction is used frequently. The replication ${ }^{18}$ of a corpus search reported in Haider (2011: 249) reproduced similar results. The finite IPP construction is frequent, the infinitival one ranges between extremely

17 "einen Übelstand, mit dem man sich schon öfter beschäftigt hat, ohne ihn indes bisher haben beseitigen zu können" (https://archive.org/stream/bub_gb_Vb0rAQAAIAAJ/ bub_gb_Vb0rAQAAIAAJ_djvu.txt)

18 Google search, restricted to „,books” (25.8.2018): „nicht hat übersehen können“: 176 hits; ,,haben übersehen zu können“: 1; ,nicht hat vermeiden können“: 814; ,haben vermeiden zu können“: 4; ,nicht hat vermeiden lassen“: 314; ,haben vermeiden zu lassen“: 0 . „nicht hat sagen dürfen“: 176; „haben sagen zu dürfen“: 0 . „nicht hat mitmachen müssen“: 48; ,haben mitmachen zu müssen“: 1 . 
rare and non-existent. So, it is easy to agree with Gunnar Bech that (6c) merely is a compromising way out of a dilemma. It is an 'official' case of acceptable ungrammaticality.

\section{Acceptable ungrammaticality}

Acceptable ungrammaticality is a psycholinguistic fact. Its explanation has to be sought in performance, not in competence, that is, not in the grammar of a given language. These phenomena tend to be underrated and overlooked, but they should be seriously taken into consideration. Acceptability and grammaticality are not coextensive. In fact, they determine the 4-cell matrix in Table 1 (Haider 2011: 224). In addition to "grammatical \& acceptable" and "ungrammatical \& unacceptable", there are two more cells. Garden path sentences are examples of grammatical unacceptability. The converse is acceptable ungrammaticality. A gardenpath expression triggers a false-negative outcome whereas acceptable ungrammaticality is an instance of a false-positive result. Informant testing gathers data in all four categories, but quite a few linguists ${ }^{19}$ tend to map them on just two of the four cells, namely acceptable = grammatical vs. unacceptable $=$ ungrammatical. This may spoil the results.

\begin{tabular}{|l|l|l|}
\hline & GRAMMATICAL & UNGRAMMATICAL \\
\hline ACCEPTABLE & fully ok & $\begin{array}{l}\text { acceptable } \\
\text { ungrammaticality }\end{array}$ \\
\hline UNACCEPTABLE & garden path, memory overload & fully deviant \\
\hline
\end{tabular}

Table 1 . The (un)grammaticality \& (un)acceptability matrix

Let us turn now to a case that is one of the trickiest candidates for reliable testing. In German, for a sizeable class of verbs, infinitival complements come in two structural varieties (Haider 2010: 311-313). A given clause may either contain an infinitival complement clause (= bi-clausal) or the very same infinitival verb may be part of the verb-cluster of a simple clause (= mono-clausal). Passivization will therefore produce two different results. In the bi-clausal structure, the case of the direct object of the infinitival verb will be unaffected by passivizing the matrix clause. In the mono-clausal variant, however, the case of the direct object will switch from accusative to nominative since it is an instance of the regular

19 They are easy to identify by their wording. They usually report their test results as results of grammaticality tests, rather than acceptability tests. 
passive applied in a simple clause. ${ }^{20}$ In the verb-cluster construction, the object of the infinitival verb is the object in a simple clause with a complex verb cluster and so it is treated like any direct object in passivization. For example, when versuchen (try) is passivized (7a), the case of the object of the clausal infinitive is not affected and remains accusative. The other option is verb clustering ( $7 \mathrm{~b}$ ). The infinitival verb is part of the verb cluster and there is no embedded clause. Therefore, the object is the direct object of the clause. If passive is applied to such a construction, the direct object of the infinitival verb is assigned nominative just like in any simple clause with a passivized transitive verb (cluster).

(7) a. dass $\left[\text { den }_{\text {Acc }} \text { Text } \mathrm{zu} \text { entziffern }\right]_{\text {clause }}$ versucht wurde that [the text to decipher] tried was 'that an attempt was made to decipher the text'

b. dass der $\operatorname{Nom}_{\text {Nom }}$ Text [zu entziffern versucht wurde $]_{\mathrm{V} \text {-cluster }}$ that the text [to decipher tried was]

In many instances of these constructions, a given serialization is structurally ambiguous, as in $(8 \mathrm{a}, \mathrm{b})$. Consequently, the passive of such utterances $(8 \mathrm{c})$ comes in two variants, either with singular subject agreement [= passive of the bi-clausal variant (8a)] or with plural subject agreement [= passive of the mono-clausal variant (8b)]. However, there are contexts that are compatible with only one of the two options, such as (8d,e). Fronting a cluster as in (8d) presupposes a cluster construction, whence the passivetriggered switch to nominative, shown by agreement. On the other hand, interveners such as propositional-attitude particles like $j a$ (indeed) are cluster-external. So, (8e) must be bi-clausal and passive would not affect the object of the infinitival clause.

(8) a. dass jemand [die Kollegen Acc $_{\text {rechtzeitig zu informieren }]_{\text {clause }}}$ that somebody [the colleagues timely to notify]

versucht hat

tried has

${ }^{20}$ The descriptive term for these data, namely "long-distance passive", is a misnomer. It is the regular passive applied to the mono-clausal infinitival construction, that is, the verbcluster construction. The bi-clausal infinitival construction does not admit any longdistance passive. Passive is clause-bound in each case (Haider 2010: 285, 319). 
b. dass jemand die Kollegen ${ }_{\text {Acc }}$ rechtzeitig [zu informieren that somebody [the colleagues timely [to notify

versucht hat $]_{\text {cluster }}$

tried has]

c. dass die Kollegen Acc $/ \mathrm{Nom}$ rechtzeitig $\mathrm{zu}$ informieren that the colleagues timely to inform

versucht wurde $_{\mathrm{Sg} .} \quad$ /wurden $_{\mathrm{Pl}}$.

tried was /were

d. [Zu informieren versucht] wurden $_{\mathrm{Pl} .}$ die Kollegen $_{\text {Nom }}$ rechtzeitig [to notify tried] were the colleagues timely

e. dass die Kollegen ${ }_{\text {Acc }}$ rechtzeitig zu informieren $j a$ versucht wurde Sg. $_{\text {. }}$ that the colleagues timely to notify PRT tried was

In elicitation tasks in class room, students easily identify the adequate case and agreement forms. In evaluation tasks, however, the very same groups behave differently. Some accept both the plural as well as the singular form in (1d), which indicates that they treat die Kollegen (the colleagues) alternatively as nominative or accusative. There usually are others who accept plural agreement also in (8e). Why that? Apparently, such a task strains the subjects when they have to juggle with case alternatives in order to arrive at a decision for their metalinguistic judgement. So, the decisive question is this. Is this a task artefact or is case assignment in verb cluster construction a vulnerable rule? It is not. What is vulnerable is the judgemental capacity of informants. An elicitation design in a clozetest format is likely to avoid such artefacts. Production, viz. elicitation, is less vulnerable than acceptability judgement. Production targets at a single utterance; acceptability judgements involve choices between potential variants of a stimulus.

The examples discussed above are examples of rules of the grammar of a particular language. As rules, they are not vulnerable and they are not continuous. Nevertheless, language users may lose control in complex expressions and they may have trouble in applying them under test conditions. These influences are real, but they are grammar-external.

\section{Rules \& grammar theory}

Let us turn now briefly to grammar theory. Since the Neogrammarian era, it has been a declared aim of linguistics to become a branch of science as a 
discipline that is able to uncover universal laws. Since the very same era, this aim has been disputed. The anthropologist Martin Joos is well remembered for his notorious dictum that languages "differ from each other without limit and in unpredictable ways" (Joos 1957: 96). Could one prove this? What would be compelling evidence? Imagine a biologist venturing such a claim: Organisms may vary without limit and in unpredictable ways? Would the scientific community have ever taken this seriously?

Presently, Construction Grammar $(\mathrm{CxG})$ disputes the existence of cross-linguistic structural invariants. Croft (2013: 210): "The basis of crosslinguistic comparison for grammatical structures must be their function, because of the great structural diversity of languages (the structural properties are essentially language-specific)." Goldberg (2013: 16): "Languages are acknowledged to vary in wide-ranging ways. The crosslinguistic generalizations that do exist are explained by domain-general cognitive processes or by the functions of the constructions involved."

If structural properties were language-specific indeed, there would be no substance for cross-linguistic structural laws, of course. However, the absence of evidence is not evidence for the absence, especially if evidence is sought in areas where there is none. Functionalists fail to detect structural 'laws' since they use 'functions' as sorting criterion. However, a given function may be implemented by means of completely different structures. So it must not come as a surprise that such an investigation strategy fails to identify cross-linguistically stable patterns. Communicative functions do not determine the structural properties of the expressions employed. ${ }^{21}$ This situation is well known in biology. The function of flying or the function of oxygen metabolism would group together entirely different structures. Therefore, biologists do not compare functions; they compare structures. Biologists sort homologically, not analogically. CxG researchers sort analogically and consequently fail to uncover invariants since crosslinguistic invariants are properties of homological and not analogical areas of grammar.

In fact, the properties of linguistic structures are cross-linguistically narrowly constrained. This tends to be overlooked in functional typologies. There are empirically well-grounded candidates for cross-linguistically

21 The correlation between structures and functions fails in both directions. Functions do not determine structures, and structures do not determine functions, but they restrict them. Question formation, for instance, employs diverse grammatical structures, which are subject to cross-structural constraints (cf. Haider 2010, ch. 5), though. On the other hand, interrogative constructions are functionally diverse; see Newmeyer (2010: 302303). 
predictable structural constraints, see Haider (2015a), (2018); Haider \& Luka Szucsich (2018). ${ }^{22}$

Both, languages and living organisms are products of ongoing processes of evolution. ${ }^{23}$ For organisms, it is evolution on the level of genetic representations. For languages, it is evolution on the level of cognitive representations of linguistic structures and rule systems (Haider 2015b). Even if the theories of biological evolution and the evolution of grammars are not disposed to predict the outcomes of on-going evolution, they are able and obliged to characterize the viable and unviable paths of evolutionary changes and thereby delimit possible and impossible developments (cf. Newmeyer 2005).

What would be an example of a possible versus an impossible grammatical development? If the grammar of Russian changed and became similar to the grammar of English, this would be a predictable change from a language with undetermined directionality of (verbal) heads to an SVO language (Haider \& Szucsich 2018). Concomitantly, the inflection system is likely to get reduced, if not eliminated. An impossible change is the inverse, namely a change from an English-type to a Russian-type grammar. No known English-like language has ever developed into a language like Russian, with 'free' V-Positioning and the recruitment of rich nominal and verbal inflection. Why is that?

There seem to be irreversible clines in Grammar change. For instance, properties supported by the declarative memory system (e.g. grammatical functions differentiated by morphological paradigms) are replaced by properties supported by the procedural memory system (e.g. grammatical functions differentiated by structural positions), but not vice versa. Cognitively, applying a structural rule seems to be less costly than memorizing, retrieving and controlling an amount of complex morphological markers, which typically get disrupted and distorted by phonological changes. However, this is only a promoting factor in the

${ }^{22}$ Here is a small selection: (a.) The filler of filler-gap constellations precedes (and ccommands) the gap. In other words, displaced heads or phrases are fronted rather than postponed. (b.) In correctly identified SVO languages, there is an obligatory, VP-external, pre-verbal structural subject position. In the absence of a subject phrase, the position is filled with an expletive. In VSO and in SOV languages, there is no obligatory subject position and therefore no room for subject expletives. (c.) Left adjuncts of head-initial phrases must be head-adjacent. (d.) Head-initial phrases are strictly ordered; head-final phrases allow for order variations.

23 Evolution happens whenever the variants of a self-reproducing system are exposed to constant and blind selection. 
cognitive evolution of grammars, not a causal one, lest every Slavic language would by now resemble Bulgarian, in its morphologically deprived modern form.

A crucial factor seems to be the irreversibility of entropy-changing processes that holds also for cognitive information processing systems. Morphological decay increases (local grammatical) entropy, ${ }^{24}$ that is, the form of the given NP is compatible with more grammatical functions than a form with a clearly marked case would. A stable structural system of grammatical functions renders possible and invites the loss of morphology.

The reversal - decrease of entropy ${ }^{25}$ in a system with little or no grammatical morphology by introducing morphological distinctions - is impossible in closed $^{26}$ systems. Morphological decay destroys information. Such information cannot be regained. Morphological decay is an irreversible process. It is safe, for instance, to assume that a language like Chinese will never develop a grammar with a morphological inflection system that parallels Latin or Sanskrit. Nevertheless, typologists consider the possibility of a typological cycle (Crowley \& Bowern, ch. 12) that proceeds from agglutinating via inflecting to isolating and then back again. Igartua (2015:676), however, emphasizes that "language-external causes (contact influence of a particular kind) [...] commonly lie behind the reverse morphological change." There is no cycle but only a one-way road from inflected to isolating languages. The vulnerable part shows in morphological decay as a phonologically caused collateral 'damage'.

Let us finally ask whether a cross-linguistic grammatical 'law' could be a vulnerable law. Could this simply mean that is not operative in the totality of its domain of application? In other words, could the law allow for "exceptions"? In science, such a law would not be considered a universal law. Exceptions invalidate a law (and do not "prove the rule", contrary to a popular but mistaken ${ }^{27}$ saying). If there is an anomaly, this cannot be captured by an exception allowance for the law. An "exception"

24 Roughly, entropy can be thought of as the amount of variance the system allows.

25 Max Planck (1926): "Every process occurring in nature proceeds in the sense in which the sum of the entropies of all bodies taking part in the process is increased. In the limit, i.e. for reversible processes, the sum of the entropies remains unchanged."

26 Linguistically, a closed system is a language that develops without significant contact language influences.

27 From Cicero's defence of L. Cornelius Balbo (56 B.C.): Exceptio probat regulam in casibus non exceptis - The exception confirms the rule in the not excepted cases. This means that a granted exception to a regulation proves the existence of the regulation, but it does not mean that a rule is confirmed by an exception. 
is nothing but confuting evidence. In this case, either the law is wrong or there is a third factor that intervenes. This third factor must be detectable and verified.

In science, a famous example is the apparently exceptional orbit of Uranus detected in 1821. Its orbit deviates from Newton's laws of motion and gravitation. There is a discrepancy of 43 seconds of arc per century. In 1846, Urbain Le Verrier postulated a perturbing planet - Neptune and calculated the position of this unknown planet. Equipped with this information, the astronomer Johann Gottfried Galle identified Neptune shortly after and thereby re-confirmed Newton's theory (Lequeux 2013).

Another long-standing problem was the precession of the perihelion of Mercury. The orbit of Mercury does not behave as told by Newton's equations. Again, in 1859, Le Verrier postulated a perturbing factor, namely a hypothetical, tiny planet that he named Vulcanus. However, nobody has ever been able to spot it. In 1916, Albert Einstein showed that the theory of general relativity accounts for the Mercury anomaly. In fact, this was the only available and immediately positive evidence for his theory at that time (Lambourne 2010, ch. 7).

These two episodes show that an anomaly may be negative or positive. If the original theory can be shown to be correct, it is positive; if not, the original theory is in danger. It is very likely to be refuted by the anomaly. Newton's theory turned out to be a special case within the theory of general relativity. As a universal theory of moving bodies in the universe, Newton's theory is incorrect.

In general, assuming an intervening third factor as account for an anomaly is a licit initial move. However, this assumption remains just an auxiliary hypothesis protecting a potentially wrong theory until is has been thoroughly tested and shown to be correct on the basis of independent evidence. Otherwise, the auxiliary hypothesis is 'vulcanic'. ${ }^{28}$

Theoretical principles are universal principles by their very nature. A scientific law is a universally valid generalization. For every instance within the domain of application of the universal principle, the outcome

$\overline{28}$ Here is an example from grammar theory: In Generative Grammar, a Vulcanus-approach for saving an allegedly universal EPP law (= Every clause has a subject) is the concept of an „empty expletive.“ This empty item is deemed to prevent a subject position from ending up as empty [sic!]. However, any Romance pro-drop language contradicts this assumption. In all these languages, a clause with the standard passive applied to an intransitive verb is ungrammatical. In the non-pro-drop languages such as French, an expletive pronoun saves grammaticality. Consequently, an empty expletive would save intransitive passives in pro-drop languages (Haider 2019). 
must match the prediction. A universal principle cannot have exceptions, by definition. If there were exceptions, it would not be a universal but merely a partial description of some facts.

In sum, grammars establish discrete sets. An expression is either grammatically well-formed or it is not. The behaviour of human beings, who put their grammars to use, is continuous. The grammatical capacities are but one module of our rich cognitive inventory. What we observe in experiments is the activity of a complex system of cognitive capacities and the outcome is a superposition of various layers of cognitive decisionmaking.

It is a demanding task for theoretical and experimental linguists to disentangle and factorize the contributions of the various contributing modules. It is extremely difficult to isolate the contributions of a single module, that is, the grammar module. To take an entire data mishmash at face value and conclude that grammatical rules are basically fuzzy is as easy as unenlightening. Grammatical rules are not fuzzy. It is the language user who is fuzzy. A scientific approach factorizes the observed data and, if successful, demonstrates how the initially perplexing data are an understandable result of the complex interaction of less complex subsystems.

\section{7. (In-)Stability of rule systems}

Finally, 'vulnerable' may be understood as 'unstable'. Some rules may be said to be vulnerable because they tend to be replaced by other rules in dialectal varieties or in diachronic progression. Typical examples are rules that have been conserved or imposed by normative efforts and do not fit into the given grammar system. In German, for instance, double accusative (Acc-Acc) verbs have been enforced by prescriptive grammars. In today's colloquial German, for instance, lehren ('teach') is not used as a double accusative verb, contrary to the prescriptive norm. $(9 a, b)$ are excerpts from corpora of 18 th century German. In present day standard German, the dative pronouns in $(9 \mathrm{~b}, \mathrm{c})$ have to be accusative pronouns, but colloquial German prefers Dat-Acc. (9c) is a dialectal example (North-Middle Bavarian), with the Standard German rendering in (9d). In the permissive lassen ('let') construction (9c), Bavarian-Austrian dialects keep using Dat-Acc instead of standard German Acc-Acc. 
(9) a. Man lehrte $\operatorname{mir}_{\text {Dat }}$ die Rechenkunst. one taught me the numeration

b. Sie ließ $\mathrm{ihm}_{\text {Dat }}$ wissen, dass sie glücklich entbunden sei. she let him know that she happily delivered has

c. Loß ia'n do heiraddn, waun's'n heiraddn wü let her $r_{\text {Dat }}$-him ${ }_{\text {Acc }}$ just marry, if-she Nom $_{\text {-him }}^{\text {Acc }}$ marry wants

d. Lasse sie $_{\text {Acc }} i_{\text {Acc }}$ doch heiraten, wenn sie ihn heiraten will. let her ${ }_{A c c}-$ him $_{A c c}$ just marry, if-she Nom $_{\text {-him }}$ Acc marry wants

Another outlier is brauchen ('need') as the only modal verb that selects a $z u$-infinitive (10a) rather than the bare infinitive. In spoken German, this verb is treated as a regular modal, that is, a verb that selects a bare infinitive (10b).

(10) a. Man braucht das nicht $z u$ lernen. one needs this not to learn

'One does not need to learn it.'

b. Man braucht das nicht lernen.

one needs this not learn

'One needs not learn it.'

In a more general perspective, the well-known and cross-linguistically recurrent Jespersen-cycle in negation systems (Jespersen 1017, Van der Auwera 2009), for instance, attests a general diachronic vulnerability of the morphological implementation of negation systems based on unstressed affixes and unstressed particles. The interplay between morphological weakening on the one hand and compensatory strengthening (i.e. by means of additional markers) triggered by information structuring on the other hand gears the cycle on a diachronic scale.

\section{Summary}

What test subjects are processing and judging in 'grammaticality judgement tasks' is the acceptability of stimulus items. An acceptability rating is the aggregate of a number of independent factors. Grammatical well-formedness is merely one of these factors. The ingenuity of the experimenters is vital for devising test designs that are in a continuous 
relation to the grammatical underpinnings and eliminating distracting factors. Experimental syntax is still an underdeveloped field, unfortunately.

The rules of human grammars are discrete, they are not weighted, and they are not inherently vulnerable. What is vulnerable is the execution of the mentally represented, discrete grammar in language processing. Metalinguistic tasks, such as judging the 'grammaticality' of an expression are particularly vulnerable since language users do not have conscious analytic access to their mental grammar system. Consequently, an (un-) acceptability impression cannot be factorized into its components introspectively. The grammar system is cognitively encapsulated and no language user is able to consciously trace and isolate its effects in the whole ensemble of processes that constitute the language processing capacity.

Acknowledgements: I gratefully acknowledge that the paper has benefitted significantly from reviewing and notably from the insightful comments, recommendations, and criticism by Ken Ramshøj Christensen.

\section{References}

Bech, Gunnar. 1963. Grammatische Gesetze im Widerspruch. Lingua 12. 291299.

Boersma, Paul \& Bruce Hayes. 2001. Empirical tests of the gradual learning algorithm. Linguistic Inquiry 32(1). 45-86.

Cowart, Wayne. 1997. Experimental syntax. Applying objective methods to sentence judgements. Thousand Oaks, CA: Sage Publications.

Crowley, Terry \& Claire Bowern. 2010. An introduction to historical linguistics. Oxford University Press.

Croft, William. 2013. Radical construction grammar. In Hoffmann, Thomas \& Graeme Trousdale (eds.) 211-232. The Oxford handbook of construction grammar. Oxford University Press.

Featherston, Sam. 2008. Thermometer judgements as linguistic evidence. In Claudia. M. Riehl \& Astrid Rothe (eds.), Was ist linguistische Evidenz?, 69-91. Aachen: Shaker Verlag.

Frazier, Lyn. 2015. Two interpretive systems for natural language? Journal of Psycholinguistic Research 44(1). 7-25.

Goldberg, Adele. 2013. Constructionist approaches. In Thomas Hoffmann \& Graeme Trousdale (eds.), The Oxford handbook of construction grammar, 1531. Oxford: Oxford University Press. 
Haider, Hubert. 2019. On absent, expletive, and non-referential subjects. 2019. In Wolfsgruber, Anne C., Bernhard Pöll \& Peter Herbeck (eds.), Semantic and syntactic aspects of impersonality, 11-46. Linguistische Berichte. Sonderheft 26.

Haider, Hubert. 2018. A typology of head positions within a phrase and its syntactic correlates. (submitted, downloadable).

Haider, Hubert. 2015a. Head directionality - in syntax and morphology. In Antonio Fábregas, Jaume Mateu \& Mike Putnam (eds.), Contemporary linguistic parameters, 73-97. London: Bloomsbury Academic.

Haider, Hubert. 2015b. "Intelligent design" of grammars - a result of cognitive evolution. In: Aria Adli, Marco García García \& Göz Kaufmann (eds.), Variation in language: System- and usage-based approaches, 205-240. Berlin/New York: de Gruyter.

Haider, Hubert. 2011. Grammatische Illusionen - Lokal wohlgeformt, global deviant. Zeitschrift für Sprachwissenschaft 30(2). 223-257.

Haider, Hubert. 2010. The Syntax of German. Cambridge, UK: Cambridge University Press.

Haider, Hubert \& Luka Szucsich. 2018. Slavic languages - "SVO" languages without SVO qualities?

Igartua, Iván. 2015. From cumulative to separative exponence in inflection: Reversing the morphological cycle. Language 91(3). 676-722.

Jespersen, Otto. 1917. Negation in English and other languages. Copenhagen: Munskgaard.

Joos, Martin (ed.). 1957. Readings in linguistics. Washington: American Council of Learned Societies.

Keller, Frank. 2006. Linear Optimality Theory as a model of gradience in grammar. In Gisbert Fanselow, Caroline Fery, Ralph Vogel \& Matthias Schlesewsky (eds.), Gradience in grammar: Generative perspectives, 270-287. Oxford: Oxford University Press.

Lambourne Robert J. 2010. Relativity, gravitation and cosmology. Cambridge: Cambridge University Press.

Lequeux, James. 2013. Le Verrier - Magnificent and detestable astronomer. New York: Springer.

Mohri, Mehryar \& Mark-Jan Nederhof. 2001. Regular approximation of contextfree grammars through transformation. In Jean-Claude Junqua \& Gertjan van Noord (eds.), Robustness in language and speech technology, 153-163. The Netherlands: Kluwer Academic Publishers.

Newmeyer, Frederick J. 2010. Formalism and functionalism in linguistics. Wiley Interdisciplinary Reviews: Cognitive Science 1(3). 301-307. doi:10.1002/wcs.6. Newmeyer, Frederick J. 2005. Possible and probable languages: A generative perspective on linguistic typology. Oxford: Oxford University Press. 
Phillips, Colin, Matt Wagers \& Ellen Lau. 2011. Grammatical illusions and selective fallibility in real-time language comprehension. In Jeffrey T. Runner (ed.), Experiments at the interfaces (Syntax \& Semantics 37), 147-180. Bingley: Emerald Publications.

Planck, Max. 1926. Über die Begründung des zweiten Hauptsatzes der Thermodynamik. Sitzungsberichte der Preußischen Akademie der Wissenschaften. Physikalisch-Mathematische Klasse. 453-463.

Schachter Jacquelyn \& Virginia Yip 1990. Grammaticality judgments. Why does anyone object to subject extraction? Studies in Second Language Acquisition 12. 379-392.

Searle, John R. 1969. Speech acts. An essay in the philosophy of language. Cambridge: Cambridge University Press.

Van der Auwera, Johan, 2009. The Jespersen cycles. In Elly van Gelderen (ed.), Cyclical change, 35-71. Amsterdam: Benjamins. 